\title{
ASPECTOS CLÍNICOS E LABORATORIAIS DE MENINGITE PIOGÊNICA EM LACTENTES
}

\author{
Rita Lucena', Irenio Gomes ${ }^{1}$, Eduardo Cardoso³, Julieta Goes², Luciana Nunes', \\ Adriana Cardoso', Bernardo Rodrigues ${ }^{1}$, Murilo Souza ${ }^{3}$, Marco Antônio Novaes ${ }^{3}$, Ailton Melo ${ }^{4}$
}

\begin{abstract}
RESUMO - Objetivo: descrever as características clínicas e laboratoriais da meningite piogênica em lactentes. Método: informações obtidas a partir do acompanhamento prospectivo dos lactentes com meningite piogênica, admitidos no Hospital Couto Maia no período de março a dezembro de 1997, foram inseridas em um banco de dados e analisadas com auxílio de programas estatísticos. Resultados: meningite piogênica foi mais prevalente em lactentes com idade entre 6 meses e 1 ano, sendo o agente etiológico mais freqüente o Haemophilus influenzae. A letalidade global foi de $25,9 \%$ e, entre os sobreviventes, $39,3 \%$ deixaram o hospital apresentando alguma anormalidade compatível com envolvimento encefálico ao exame neurológico. Conclusão: meningite piogênica em lactentes se constitui em enfermidade com taxa de letalidade elevada, sendo, na maioria dos casos, passível de prevenção. Consideramos de grande relevância a adoção de medidas profiláticas de saúde visando redução da incidência desta enfermidade.
\end{abstract}

PALAVRAS-CHAVE: meningite piogênica, meningite bacteriana, lactentes, crianças.

Clinical and laboratorial aspects of acute bacterial meningitis in infants

ABSTRACT - Objective: to describe clinical and laboratorial characteristics of acute bacterial meningitis in infants. Method: data from the prospective follow-up of infants with acute bacterial meningitis, admitted at the Hospital Couto Maia between March and December 1997, were analyzed with specific statistical software Results: acute bacterial meningitis was more prevalent in infants with ages varying from 6 months to 1 year. The most frequent etiologic agent was Haemophilus influenzae. The global lethality was $25.9 \%$ and among the survivors $39.3 \%$ left the hospital with some abnormality in the neurological exam compatible with the brain involvement. Conclusion: acute bacterial meningitis in infants is a high lethality disease that in the majority of cases can be prevented. We consider of great relevance the adoption of health prevention strategies in order to reduce the incidence of this disease.

KEY WORDS: acute bacterial meningitis, infants, laboratorial, clinical.

Apesar dos avanços diagnósticos e terapêuticos ocorridos nosúltimosanos, meningite piogênica continua sendo um problema de saúde pública, sobretudo nos países em desenvolvimento ${ }^{1,2}$. A maioria dos estudos realizados mostra maior incidência desta enfermidade em crianças, principalmente nos dois primeiros anos de vida ${ }^{3}$. No entanto, poucas são as publicações específicas desta faixa etária. As casuísticas referentes aos lactentes habitualmente estão diluídas nos estudos mais abrangentes.

A Bahia, terceiro maior estado do Brasil, com população estimada de 13 milhões de habitantes (Censo Demográfico, 1996), é considerada zona de alta endemicidade para muitas doenças infecto-contagiosas. Em estudos prévios, realizados no Hospital Couto Maia, verificamos que, anualmente, são ad- mitidos aproximadamente 1000 casos de meningite, dos quais $60 \%$ são de etiologia bacteriana e a maioria ocorre em crianças ${ }^{4}$.

Assim, com o objetivo de melhor conhecer osaspectos clínicos e laboratoriais de meningite piogênica em lactentes, realizamos o acompanhamento dos casos ocorridos na Bahia em 1997. Esteé o primeiro estudo descritivo com coleta de dados prospectiva e abordando aspectos referentes ao envolvimento neurológico produzido pela meningite piogênica nesta faixa etária.

\section{MÉTODO}

Trata-se de estudo descritivo de série de casos de indivíduos com idade entre 28 dias e 2 anos, com diagnóstico de meningite piogênica, admitidos entre $1^{\circ}$ de março e

Divisão de Neurologia e Epidemiologia (DINEP) da Universidade Federal da Bahia (UFBA), Salvador BA, Brasil: ${ }^{1}$ Bolsistas CNPq; ${ }^{2}$ Bolsista CAPES; ${ }^{3}$ Pesquisadores da DINEP; ${ }^{4}$ Coordenador da DINEP.

Recebido 27 Agosto 2001, recebido na forma final 12 Novembro 2001. Aceito 20 Novembro 2001. 
31 de dezembro de 1997 no Hospital Couto Maia, unidade de referência para o tratamento de enfermidades infecciosas no estado da Bahia. Foram incluídos no estudo os indivíduos que preenchiam pelo menos um dos seguintes critérios para meningite piogênica: cultura ou coloração pelo método de Gram positivos no líquido cefalorraquidiano (LCR) ou celularidade $\geq 1000 \mathrm{cels} / \mathrm{mm}^{3} \mathrm{com}$ predomínio de neutrófilos no LCR. Foram excluídos lactentes com história de meningite recorrente ou pós-traumática ou portadores de transtornos neurológicos prévios.

Anamnese e exame neurológico padronizado foram realizados durante admissão hospitalar e, a partir daí, os lactentes incluídos foram acompanhados diariamente por uma equipe de neurologistas até o desfecho. Síndrome do neurônio motor superior (SNMS) foi identificada através da presença de hiperreflexia profunda, espasticidade, sinal de Babinski, clônus ou déficit motor; síndrome extrapiramidal foi caracterizada por ocorrência de rigidez plástica ou movimentos involuntários; e síndrome cerebelar por ataxia, disdiadococinesia, dismetria ou disartria. A presença de hipertensão intracraniana (HIC) foi determinada através da detecção de papiledema ou aumento progressivo de perímetro cefálico.

As informações referentes aos dados clínicos e laboratoriais foram inseridas em banco de dados e analisadas a partir de programas estatísticos (EPI-info ver. 6,01b e SPSS ver. 6,1 ). A estatística descritiva incluiu média, mediana e desvio padrão. Teste do $\chi 2$ foi aplicado para avaliar relação entre letalidade e faixa etária e letalidade e agente etiológico e entre faixa etária e agente etiológico. Foram consideradas significantes associações com $p \leq 0,05$. O projeto foi aprovado pela comissão de ética do Hospital Couto Maia.

\section{RESULTADOS}

Entre $1^{\circ}$ de março e 31 de dezembro de 1997, foram admitidas no Hospital Couto Maia 116 crianças com idade entre 28 dias e 2 anos e que preenchiam pelo menos um dos critérios descritos para meningite piogênica.

O tempo de doença, definido como o intervalo entre o primeiro sintoma (febre, vômito ou crise epiléptica) e o diagnóstico, foi $\leq 1$ dia em $27,6 \%,>1$ dia e $\leq 3$ dias em 34,5\% e superior a 3 dias em $37,9 \%$. Durante a admissão hospitalar, sinais clínicos referentes ao acometimento respiratório foram identificados em $52,6 \%$. Otite média foi observada em 5,2\% dos casos e infecção bacteriana de pele, em $3,4 \%$. Rash purpúrico ou petequial foi verificado em $5,2 \%$ dos lactentes.

Os sintomas mais freqüentemente relatados foram febre, vômitos, crises epilépticas e sonolência (Tabela 1). Exame neurológico anormal foi observado em $53,4 \%$ dos casos à admissão. As principais anormalidades foram irritação meníngea e diminui-
Tabela 1. Variáveis demográficas e clínicas em lactentes com meningite piogênica na admissão hospitalar.

\begin{tabular}{|c|c|c|}
\hline Variável & $\mathrm{N}$ & $\%$ \\
\hline \multicolumn{3}{|l|}{ Gênero } \\
\hline Masculino & 68 & 58,6 \\
\hline Feminino & 48 & 41,4 \\
\hline \multicolumn{3}{|l|}{ Procedência } \\
\hline Capital & 58 & 50,0 \\
\hline Interior & 58 & 50,0 \\
\hline \multicolumn{3}{|l|}{ Faixa etária } \\
\hline$<6$ meses & 41 & 35,3 \\
\hline $6-11$ meses & 47 & 40,5 \\
\hline 12 - 24 meses & 28 & 24,1 \\
\hline Febre & 113 & 97,4 \\
\hline Vômito & 88 & 75,9 \\
\hline Crises epilépticas & 40 & 34,5 \\
\hline Uso prévio de antibióticos & 26 & 22,8 \\
\hline \multicolumn{3}{|l|}{ Tempo de doença } \\
\hline$\leq 1 \mathrm{dia}$ & 32 & 27,6 \\
\hline$>1$ dia $\mathrm{e} \leq 3$ dias & 40 & 34,5 \\
\hline$>3$ dias & 44 & 37,9 \\
\hline Infecção respiratória alta & 61 & 52,6 \\
\hline Otite & 6 & 5,2 \\
\hline Infecção de pele & 4 & 3,4 \\
\hline Presença de rash & 6 & 5,2 \\
\hline
\end{tabular}

ção do nível de consciência. A Tabela 2 mostra a distribuição das principais anormalidades encontradas.

$\mathrm{O}$ estudo hematológico revelou anemia $(\mathrm{Hb}<$ $11 \mathrm{~g} \%$ ) em $90 \%$ dos casos. Contagem global de leucócitos em sangue periférico $\geq 18.000 / \mathrm{mm} 3$ foi identificada em 38,9\% e 11,15\% apresentavam contagem inferior a $6000 / \mathrm{mm}^{3}$. Em $62,5 \%$, verificamos desvio para esquerda (razão segmentados/bastonetes < 16). Tomografia computadorizada de crânio foi realizada em 15 pacientes. A complicação mais frequente foi encefalite $(66,7 \%)$, seguida de coleção subdural $(33,3 \%)$ atrofia cortical $(20 \%)$ e abscesso cerebral $(13,3 \%)$. Ventriculite foi detectada em $6,7 \%$ e hidrocefalia em $4,3 \%$ dos exames.

A distribuição dos dados do estudo do líquido cefalorraqueano realizado à admissão hospitalar é visto na Tabela 3. Isolamento de bactéria através do método de Gram ocorreu em $80,7 \%$ e da cultura do líquor em $69,8 \%$. Em 71,6\% dos casos, ocorreu identificação do agente etiológico através da cultura liquórica ou hemocultura. Haemophilus influenzae foi o agente mais comum $(65,4 \%)$, seguido deNeis- 
Tabela 2. Características do exame neurológico identificadas em lactentes com meningite piogênica durante admissão hospitalar.

\begin{tabular}{lcc}
\hline Variável & N & $\%$ \\
\hline Exame neurológico & & \\
$\quad$ Normal & 54 & 46,6 \\
$\quad$ Anormal* & 62 & 53,4 \\
Diminuição do nível da consciência & 42 & 36,2 \\
Sonolência & 16 & 13,8 \\
Rigidez de nuca & 84 & 72,4 \\
Brudzinski & 34 & 29,3 \\
Kernig & 11 & 9,5 \\
Lasègue & 4 & 3,4 \\
Síndrome de irritação meníngea & 89 & 76,7 \\
Alteração de nervos cranianos & 10 & 8,6 \\
Síndrome do NMS** & 32 & 27,6 \\
Síndrome cerebelar & 9 & 7,8 \\
Síndrome extrapiramidal & 2 & 1,7 \\
Síndrome de HIC*** & 5 & 4,3 \\
\hline
\end{tabular}

*exceto irritação meníngea; **neurônio motor superior; ***hipertensão intracraniana.

seria meningitidis (13,6\%) eStreptococcus pneumoniae (19,8\%). Staphilococcus aureus foi isolado em apenas um caso.

A Tabela 4 mostra que a prevalência dos três principais agentes foi semelhante até seis meses de ida- de e que, a partir daí, ocorreu predomínio de $H$. influenzae $(p=0,008)$. Durante a internação, $79,3 \%$ dos lactentes foram submetidos à corticoterapia (dexametasona 0,6 mg/kg/dia por 5 dias) e 19,8\% utilizaram drogas anti-epilépticas.

Em relação ao desfecho, 25,9\% evoluíram para o óbito e, entre os sobreviventes, 39,3\% deixaram o hospital apresentando alguma anormalidade no exame neurológico sugestiva de dano encefálico. A maior taxa de letalidade foi observada nos casos causados por $S$. pneumoniae (35,3\%), seguido de $N$. meningitidis $(18,2 \%) \mathrm{eH}$. influenzae $(11,1 \%)$, com $p=0,06$. A letalidade foi maior entre os indivíduos com meningite de etiologia não identificada (45,5\%) quando comparada com os de etiologia identificada $(18,1 \%)$, com $p=0,002$. Não foi observada diferença nas taxas de letalidade entre as faixas etárias $(p=0,3)$.

\section{DISCUSSÃO}

Tradicionalmente, a meningite em lactentes tem sido considerada enfermidade de maior dificuldade diagnóstica pela inespecificidade dos sintomas clínicos no início da doença ${ }^{5}$. No entanto, em nossa população, verificamos taxa elevada de rigidez de nuca e de crises epilépticas. Outro aspecto interes-

Tabela 3. Características do líquido cefalorraqueano identificadas em lactentes com meningite piogênica durante admissão hospitalar.

\begin{tabular}{|c|c|c|c|c|}
\hline Variável & $\mathrm{N}$ & $\%$ & Média \pm desvio-padrão & Mediana \\
\hline \multicolumn{5}{|l|}{ Glicose (mg\%) } \\
\hline$\leq 40$ & 101 & 87,1 & $27,4 \pm 11,7$ & 20,0 \\
\hline$>40$ & 15 & 12,9 & & \\
\hline \multicolumn{5}{|l|}{ Proteínas (mg\%) } \\
\hline$\leq 40$ & 4 & 3,5 & & \\
\hline$>40 \mathrm{e} \leq 200$ & 35 & 30,4 & $318,0 \pm 149,0$ & 300,0 \\
\hline$>200$ & 76 & 66,1 & & \\
\hline \multicolumn{5}{|l|}{ Celularidade (cels $/ \mathrm{mm}^{3}$ ) } \\
\hline$<1.000$ & 18 & 15,7 & & \\
\hline$\geq 1.000$ e $<5.000$ & 42 & 36,5 & $5.413,7 \pm 3.973,5$ & $4.650,0$ \\
\hline$\geq 5.000$ & 55 & 47,8 & & \\
\hline
\end{tabular}

Tabela 4. Distribuição de faixa etária de acordo com a etiologia em lactentes com meningite piogênica na Bahia.

\begin{tabular}{lccc}
\hline Idade & H. influenzae $(\%)$ & N. meningitidis (\%) & S. pneumoniae (\%) \\
\hline$<6$ meses & $10(35,7)$ & $7(25,0)$ & $11(39,3)$ \\
$\geq 6$ meses e $<1$ ano & $29(76,3)$ & $4(10,5)$ & $5(13,2)$ \\
$\geq 1$ ano & $15(93,7)$ & $0(0,0)$ & $1(6,3)$
\end{tabular}


sante é a alta freqüência de sinais de envolvimento encefálico durante a admissão hospitalar, mostrando que a realização de exame neurológico criterioso é uma ferramenta importante no diagnóstico. Em estudo prévio realizado no mesmo hospital e incluindo indivíduos com idade inferior a 13 anos, verificamos maior freqüência de óbito entre os casos de meningite piogênica de etiologia identificada, ao contrário do que observamos neste estudo em lactentes ${ }^{6}$. Outro aspecto é a maior taxa de letalidade produzida pela $N$. meningitidis quando comparada com o $\mathrm{H}$. influenzae em indivíduos com idade inferior a dois anos, o que provavelmente mostra o comportamento mais agressivo do meningococo nesta faixa etária.

Embora o estudo do LCR seja de fácil execução e baixo custo, a alta proporção de indivíduos procedentes do interior do Estado mostra a dificuldade de acesso a esta ferramenta diagnóstica em cidades menores. Considerando a grande área territorial do estado da Bahia, este é um fato que pode potencialmente implicar em atraso do diagnóstico com repercussões negativas no prognóstico global. Infelizmente, a realização de estudos de neuroimagem ainda está restrita a grupo de maior risco, e a dificuldade de detecção de possíveis complicações através destas técnicas pode também se constituir em fator agravante em nossa população.

Em nosso estudo, verificamos taxa de letalidade elevada, próxima àquelas verificadas em países africanos $^{7,8}$. Entre os sobreviventes, muitos persistiram com anormalidades neurológicas, o que determina maior possibilidade de ocorrência de seqüelas a longo prazo. Estes dados são preocupantes, sobretudo porque a maior parte dos casos poderia ter sido evitada através do uso de vacina conjugada contra o Haemophilus influenzae. Nos países em que esta medida foi adotada, verificou-se redução muito acentuada da incidência de meningite, sobretudo nos primeiros cinco anos de vida ${ }^{9-11}$. Recentemente, em Is- rael, a implantação de um programa de vacinação em massa contra Haemophilus influenzae tipo b mostrou redução significativa da incidência de doença invasiva por este agente em crianças ${ }^{12}$. Nosúltimos anos, tem sido discutida a viabilidade de utilização de vacina conjugada contra os três principais agentes envolvidos na ocorrência de meningite piogênica em crianças. No entanto, o alto custo das vacinas conjugadas determinará, sem dúvida, uma limitação importante para sua utilização em países pobres ${ }^{13}$. Assim, os nossos dados nos alertam sobre a necessidade premente da implantação de programa de saúde coletiva, com vacinação em massa da população de maior risco, para reduzir a mortalidade ea letalidade por meningite piogênica na Bahia.

\section{REFERÊNCIAS}

1. Akpede GO. Presentation and outcome of sporadic acute bacterial meningitis in children in the African meningitis belt: recent experience from northern Nigeria highlighting emergen factors in outcome. West Afr J Med 1995;14:217-226.

2. Hussey G, Schaaf H, Hanslo D, et al. Epidemiology of post-neonatal bacterial meningitis in Cape-Town children. S Afr Med J 1997;87:51-56.

3. Bhat BV, Verma IC, Puri RK, Srinivasan S, Nalini P. A profile of pyogenic meningitis in children. J Indian Med Assoc 1991;89:224-227.

4. Lucena R, Gomes I, Ferreira A, et al. Características clínicas e laboratoriais de meningites piogênicas em crianças. Arq Neuropsiquiatr 1996;54:571-576.

5. Akpede GO, Abiodun PO, Ambe JP, Jacob DD. Presenting features of bacterial meningitis in young infants. Ann Trop Paediatr 1994;14:245-252.

6. Gomes I, Melo A, Lucena R, et al. Prognosis of bacterial meningitis in children. Arq Neuropsiquiatr 1996;54:407-411.

7. Moyen G, Mbika-Cardorelle A. Bacterial meningitis in infants and children at the Brazzaville University Hospital. Arch Pediatr 1999;6:108-109.

8. Campagne G, Schuchat A, Dijbo S, Ouss'eini A, Ciss'e L, Chippaux JP. Epidemiology of bacterial meningitis in Niamey, Niger, 1981-1996. Bull WHO 1999;77:499-508.

9. Novakova E, Gessner BD, Olear V. Incidence of Haemophilus influenzae type $\mathrm{b}$ meningitis among children less then 5 years of age in Slovakia. Eur J Clin Microbiol Infect Dis 1999;18:409-413.

10. Urwin G, Yuan MF, Feldman RA. Prospective study of bacterial meningitis in North East Thames region, 1991-3, during introduction of Haemophilus influenzae vaccine. BMJ 1994;309:1412-1414.

11. Mulholland EK, Hoestermann A, Suara RO, et al. Haemophilus influenzae type $\mathrm{b}$ meningitis after three doses of vaccine (letter). Lancet 1994, 343:794.

12. Dagan R, Fraser D, Roitman M et al. Effectiveness of a nationwide infant immunization program against Haemophilus influenzae type b. Vaccine 1999;17:134-141.

13. Peltola H. Prophylaxis of bacterial meningitis. Infect Dis Clin N Am 1999;13:685-710 